\title{
Good and Bad Reasoning about COVID-19
}

\author{
LOUISE CUMmings
}

\author{
Department of English \\ The Hong Kong Polytechnic University \\ Hung Hom, Kowloon \\ Hong Kong \\ louise.cummings@polyu.edu.hk
}

\begin{abstract}
The COVID-19 pandemic presents argumentation theorists with an opportunity to reflect on the ways in which people, agencies, and governments respond to the emergence of a new virus. Reponses have revealed a range of judgements and decisions, not all of which are rationally warranted. This article will examine errors in reasoning, several of which have reduced the public's compliance with important health measures. This article will also analyse rationally warranted reasoning about COVID-19 employed by public health agencies. In examining instances of good and bad reasoning during the COVID-19 pandemic, we can begin to construct a taxonomy of arguments that have facilitated and hindered individual and collective responses during this public health emergency.
\end{abstract}

Résumé: La pandémie de COVID-19 offre aux théoriciens de l'argumentation l'occasion de réfléchir sur la manière dont les gens, les agences et les gouvernements réagissent à l'émergence d'un nouveau virus. Les réponses ont révélé une gamme de jugements et de décisions qui ne sont pas tous rationnellement justifiés. Cet article examinera les erreurs de raisonnement, dont plusieurs ont réduit la conformité du public à des mesures sanitaires importantes. Cet article analysera également le raisonnement rationnellement justifié au sujet du COVID-19 employé par les agences de santé publique. En examinant les exemples de bons et de mauvais raisonnements pendant la pandémie de Covid-19, nous pouvons commencer à construire une taxonomie d'arguments qui ont facilité et entravé les réponses individuelles et collectives lors de cette urgence de santé publique.

Keywords: analogy, argument from ignorance, coronavirus, COVID-19, equivocation, fallacy, infectious disease, pandemic, public health, reasoning

\section{Introduction}

Global health authorities are facing their most serious challenge in the last 100 years. In just six months, a novel coronavirus has 
caused death and suffering on a scale that has not been witnessed since the Spanish flu pandemic of 1918. As of June 9, 2020, the World Health Organization had reported that this virus has infected over 7 million people worldwide and claimed the lives of 404,396 people (World Health Organization 2020a). The economic damage caused by the emergence of this virus is also beginning to be quantified. The World Bank (2020) estimates that the pandemic is expected to plunge most countries into recession in 2020, resulting in the highest percentage of countries experiencing a reduction in their per capita outputs since 1870 . This pandemic has seen governments and health agencies struggle to institute timely measures to protect human health. As one might expect, not all these measures have had their desired effect, with many introduced in a rushed and chaotic fashion as the full extent of the crisis became apparent. It will be instructive for our handling of future pandemics to look at the reasoning that shaped national and individual responses to COVID-19 and to see where this reasoning provided a logically sound basis for decision and action. That is the aim of this article.

The data that will inform the following discussion are of two types. Between January and June 2020 - approximately the first six months of the pandemic-I was a resident in the UK. I had originally travelled there from Hong Kong for one month with the purpose of collecting data for my research into neurodegenerative disorders in adults (another area of my work). However, as events in the central Chinese city of Wuhan unfolded and then a nationwide lockdown came into force in the UK, I decided to delay my return to Hong Kong and to continue working in the UK. While there, I observed and recorded responses, all from people who were personal acquaintances, to the new health measures that were beginning to take effect. These responses, 30 in total, provide a small set of data from which four extracts will be used in this article. National governments around the world also put a wide range of health measures in place to slow the spread of the virus. Many of these measures were guided by recommendations from the United Nations global health agency, the World Health Organization (WHO). Other measures went further than the recommendations made by WHO; for example, the UK advised individuals 
to practice social distancing of two metres as opposed to following WHO's recommendation of one metre. Substantial health literature on COVID-19 was produced during the pandemic by the health departments of national governments and public health agencies, such as the WHO and the US Centers for Disease Control and Prevention (CDC). This literature will provide the second type of data that I will use in this article.

\section{COVID-19: Some background}

We must begin with an important terminological distinction. COVID-19 is not the name of a virus. Rather, it is the name of the disease that is caused by the novel coronavirus. The name 'COVID-19' was announced by the World Health Organization on February 11, 2020. This followed the announcement on the same day that the International Committee on Taxonomy of Viruses had named the virus that causes COVID-19 disease 'severe acute respiratory syndrome coronavirus 2 (SARS-CoV-2).' SARS-CoV2 is a beta coronavirus like SARS-CoV (the virus that causes Severe Acute Respiratory Syndrome) and MERS-CoV (the virus that causes Middle East Respiratory Syndrome), which emerged in 2003 and 2012, respectively. SARS-CoV-2 is close to a bat SARSlike coronavirus BatCov RaTG13 (identity 96\%). While bats appear to be the reservoir for novel coronavirus (i.e., the virus has a zoonotic origin), the intermediate host(s) has not yet been identified. Initial indications are that Malayan pangolins may be an intermediate host (Lam et al. 2020).

Because COVID-19 appeared to emerge in the central Chinese city of Wuhan in Hubei Province, much of the early scientific work on the virus was conducted by Chinese scientists. On January 12,2020 , China publicly shared the genetic sequence of the new virus. Human-to-human transmission of the virus was suspected early in the Wuhan outbreak and was first acknowledged in a press briefing by WHO on January 14, 2020. It is now known that human-to-human transmission occurs primarily by means of droplets and fomites (i.e., objects and materials that are likely to carry infection, such as clothes, utensils, and furniture). Although there is some evidence of transmission via the fecal-oral route, this 
is not thought to be a major driver of transmission. The attack rate of the virus - the proportion of people who become infected with SARS-CoV-2 when exposed to an infected individual-varies with setting. Attack rates of $38 \%, 43.5 \%$, and $86.7 \%$ have been reported in a church setting in the USA, a call centre in South Korea, and a choir practice in the USA, respectively (James et al. 2020; Park et al. 2020; Hammer et al. 2020). SARS-CoV-2 is more transmissible in households than either SARS-CoV or MERS-CoV, with attack rates reported of 13.8\% (household contacts defined as all close relatives) and 19.3\% (household contacts defined as those at the same residential address) (Jing et al. 2020).

The symptoms of COVID-19 appear between 2 and 14 days after exposure to the virus. Originally thought to include just fever, cough, and shortness of breath, the symptoms of COVID-19 have been expanded to include fatigue, muscle or body aches, headache, new loss of taste or smell (anosmia), sore throat, congestion or runny nose, nausea or vomiting, and diarrhea. There is some evidence that asymptomatic people can transmit the virus (Kimball et al. 2020; Pan et al. 2020). Risk factors for severe COVID-19 disease include age (greater risk $\geq 65$ years), sex (greater risk in males), ethnicity (greater risk in people from Black and minority ethnic communities), and the presence of underlying health conditions (e.g., diabetes, hypertension). In patients with severe COVID-19 disease requiring hospitalization, the mortality rate is high. In a study of patients with SARS-CoV-2 pneumonia, 32 of $52(61.5 \%)$ critically ill patients had died at 28 days, with the median duration from admission to the intensive care unit to death being 7 days (Yang et al. 2020).

\section{The UK lockdown}

On March 23, 2020, the UK Government ordered a nationwide lockdown. The measures were announced by the British Prime Minister, Boris Johnson, in a televised address to the nation from Downing Street. Under the new restrictions, people were instructed to stay at home and only leave their home for the following purposes: 
- shopping for basic necessities as infrequently as possible;

- getting one form of exercise a day-for example, a run, walk, or cycle - alone or with members of their household; - addressing any medical need, to provide care, or to help a vulnerable person; and

- travelling to and from work, but only when absolutely necessary and when the work could not be done from home.

The aim of the lockdown was to slow the spread of the virus, which, if left unchecked, threatened to overwhelm the National Health Service (NHS). The Prime Minister concluded his speech with the words "Stay home, protect the NHS, save lives."

828.

CORONAVIRUS STAY AT HOME SAVE LIVES

\section{Anyone can spread Coronavirus.}

The only reasons to leave home are:

(-) To shop for basic necessities or pick up medicine

To travel to work when you absolutely cannot work from home

(†) exercise once a day, alone or with members of your household

( Do not meet others, even friends or family

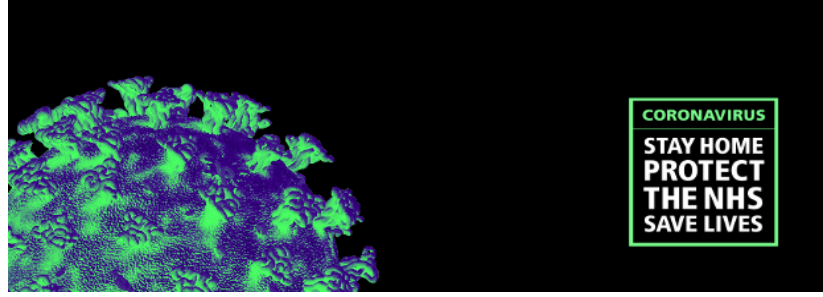

Figure 1. The public health message of the UK Government during lockdown (Contains public sector information licensed under the Open 
Government Licence v3.0. http://www.nationalarchives.gov.uk/doc/opengovernment-licence/version/3/)

This slogan came to define the key public health message of the UK Government during lockdown (see Figure 1). It was accompanied by social distancing and hygiene guidelines that required people to maintain a distance of 2 metres, to wash their hands regularly for at least 20 seconds, to cover their mouth and nose with a tissue or sleeve when coughing or sneezing, to dispose of tissues in a bin, and to avoid touching their eyes, nose, or mouth when their hands are not clean. This guidance was distributed to every home in the country in the form of a letter from the Prime Minister and an information leaflet. The leaflet also contained information for those over 70 years of age and with underlying health conditions who were considered to be at greater risk of contracting the disease. As I watched people adjust to the new restrictions and guidance, I was struck by some of the responses and behaviours that I observed. For example, a 40-year-old male friend decided to spend a weekend with his parents, who were both over 70 years of age. This required that he travel by public transport (train) between his hometown and his parents' home. This course of action violated at least three of the restrictions in place:

- It represented non-essential travel (people were only allowed to travel for work purposes and only then when they could not work from home).

- His parents were in the age group that should have been shielding from the virus.

- He spent a weekend in his parents' house where social distancing measures, specifically the requirement to maintain a two-metre distance, could not be observed.

How can we explain this behaviour? It is too easy to dismiss it as the actions of someone who is selfish or unintelligent. I know the individual who took these actions very well and he is not inclined to reckless behaviour that would jeopardize his parents and other people (e.g., fellow train passengers). Fallacy theorists already acknowledge a fallacy-secundum quid or the fallacy of acci- 
dent - in which we fail to recognize that various qualifications apply to general statements (Walton 1990; Woods 2004). For example, in saying vehicles should not park in front of the building, we recognize that if there is a fire, and the vehicle is a fire engine, then it can legitimately park in front of the building. In failing to recognize this legitimate exception to the general statement - asserting that even a fire engine should not park in front of a burning building - an arguer commits the fallacy of secundum quid. Can we not also recognize the opposite type of logical error in which qualifications are applied to general statements to which they do not belong? So, my friend understands that people are instructed not to undertake non-essential travel. However, he views travel to his parents to be a type of qualification on the general statement that people should not undertake non-essential travel and proceeds to conclude that he can undertake nonessential travel. The same logical lapse led him to devise qualifications on two further general statements, namely, the statements that elderly people should be shielded from the virus and that people from different households must maintain a two-metre distance. Accordingly, he judged that his elderly parents did not need to be shielded from the virus and that although he and his parents were from different households, they did not need to maintain a two-metre distance.

Is my friend's reasoning an example of the fallacy of converse accident (Walton 1999), where an exception to a generalization is applied to cases where the generalization should apply? In answering this, let us consider an example: we use the synthetic opiate fentanyl to control pain in people with end-stage cancer. However, we do not allow this exceptional (and warranted) use of fentanyl to justify its more widespread use by people as a recreational drug - notwithstanding the fact that this is exactly how the drug is used by many people. We still subscribe to the generalization that people should not use dangerous and addictive opiates, like fentanyl, even as we recognize that there can be warranted exceptions to this generalization, as in the case of the patient with end-stage cancer. To do otherwise is to commit the fallacy of converse accident. But my friend's reasoning is not an example of converse accident, for he is not trying to argue that others should 
undertake non-essential travel, that elderly people in general should not shield themselves from the virus, and that people should not maintain a two-metre distance. Instead, he is arguing that these conditions should only apply to him and his elderly parents. Moreover, unlike the patient with end-stage cancer, where the use of fentanyl is entirely warranted-as a warranted exception to the generalization-my friend's exceptional behaviour has no such rational warrant. His actions cannot be justified on grounds such as that he was delivering vital medication to his parents in the same way that the administration of fentanyl to the cancer patient is justified by the pain relief that it offers. So, my friend has not committed the fallacy of converse accident even as he reasons fallaciously:

\section{P1: People should not undertake non-essential travel during lockdown. \\ P2: My trip to my parents is an exception to the prohibition on non-essential travel. \\ C: Therefore, I am entitled to undertake a trip to my parents.}

My friend's fallacious reasoning is exposed at the point when he might attempt to justify premise two. As we have seen, there is no justification of this premise on grounds such as he was delivering vital medical supplies to his parents or providing some similar form of support. My friend views a "hard" generalization-a government directive expressed in premise one-as a "soft" generalization to which he considers himself (incorrectly) to be a legitimate exception. At the same time, he is perfectly prepared to acknowledge that the "hard" generalization should be observed by everyone else- he is not arguing that his situation should supersede the government directive for other people, as would be the case if he were committing the fallacy of converse accident. This argument illustrates one way in which people reasoned fallaciously during the UK lockdown, even people who should have known better (e.g., Dominic Cummings, one of the Prime Minister's chief advisors, engaged in similar reasoning when he decided to break lockdown rules and travel from London to Yorkshire to visit his parents). As one might expect, however, it was not the 
only type of fallacious reasoning to arise. In the rest of this section, we examine other fallacies.

The next instance of fallacious reasoning that I observed was committed by a 71-year-old retired work colleague. He wanted to meet a mutual friend socially, which is something we all did together every six months or so. This meeting was scheduled to take place just before lockdown came into force. It had already been cancelled once by my friend as she was becoming increasingly concerned by the escalating COVID-19 situation and our retired colleague had just returned from foreign travel. To try and allay her anxieties, our retired colleague suggested that instead of meeting in a public space, they could get together either in her house or in his house but that he would have to refrain from giving her a hug (our usual greeting). However, this response was a failure of relevance (Walton 1992a; 2004). The location of their meetingpublic space versus private house-was an irrelevance for my friend, who was concerned by the fact that they would be in close social contact, which was a situation that could facilitate transmission of the virus. In bringing forward the suggestion to change the location of their meeting, our retired colleague was arguing from an irrelevant premise. His argument took the following form:

My friend is concerned about being exposed to the virus through social contact.

I can address this concern by suggesting we change the location of our meeting.

Therefore, I will suggest that we meet in one of our homes rather than in a public space.

What our retired colleague failed to appreciate was that the setting of the social contact-public space or private home-did not fundamentally alter the social contact that would take place and that would pose a risk of transmission of the virus between the individuals present. The location of the meeting was essentially irrelevant when the key issue for my friend was the transmission risks associated with close social contact. Our retired colleague was not successful in persuading our mutual friend to meet him 
because of a failure of relevance of the location of the meeting to the transmission risks that close social contact posed.

A further instance of fallacious reasoning was observed in a 56year-old man who regularly visited his elderly father during the lockdown. On account of his advanced years, his father should have been shielded from the virus. This required people from other households to avoid visits to him as well as other forms of direct contact. When challenged about his actions by concerned family members, the man in question claimed that he presented no health risk to his father because he changed his clothes before entering his father's house. (It is worth remarking that this gentleman is a part-time farmer who is accustomed to changing his clothes as a means of preventing the transmission of infectious diseases he may be exposed to through his work.) This individual failed to appreciate that while his clothes may not transmit the virus to his father, he almost certainly could. His reasoning took the form of the fallacy of composition, in which he used a property of a part (his clothes) to infer the property of a whole (his body). The argument in this case is shown below:

\section{My clothes will not transmit the virus to my elderly father.}

Therefore, I will not transmit the virus to my elderly father.

There are two aspects of this argument that are problematic. First, it is assumed that clothes are a part of a person's body in much the same way that skin and hair are. However, clothes can be removed and sterilized in a way that skin and other bodily parts cannot. Second, this man's clothes may pose little or no risk of virus transmission, especially if they are washed before a home visit. Meanwhile, exhaled droplets can present a very significant risk of virus transmission. This is because fomite transmission of the virus via infected clothes and objects is only one possible route of transmission. A more efficient and hence significant route of transmission comes from the droplets that we emit when we cough, sneeze, or even just speak in the presence of other people. It is not possible to draw any conclusion about the virus transmission risk that this man poses to his father when this risk appears to be predicated upon the cleanliness or otherwise of his clothes. For 
clothes are not properly a part of a person's body. And nothing can be concluded about the risk of droplet transmission of the virus between this man and his father based on fomite transmission of the virus by means of his clothes.

The next instance of fallacious reasoning I observed during UK lockdown was committed by the 76-year-old father of a friend. As the UK Government started to ease the national lockdown, one of the restrictions that was lifted was the prohibition on people from different households meeting each other. With the easing of restrictions, people from different households were permitted to meet each other, providing they observed a two-metre distance, and any meeting took place outdoors. Shortly after this announcement was made, my friend's father was found chatting to a neighbour in his garden shed. When my friend challenged his father's behaviour, he argued as follows:

\section{People can meet with individuals from a different household outdoors. \\ My garden shed is outdoors. \\ Therefore, I can meet one of my neighbours in my garden shed.}

The error in this reasoning is one of equivocation in that the word 'outdoors' is used with different senses or meanings in the two premises of the argument (Powers 1995; Walton 1996). In the first premise, the word 'outdoors' means an unenclosed space in the open air. It is known that the virus that causes COVID-19 transmits more easily between people who are in poorly ventilated, confined spaces. By meeting in the open air, the risk of transmission can be considerably reduced. However, in the second premise, the word 'outdoors' has a different sense or meaning that was not intended by the Government in its updated advice. In this premise, 'outdoors' means outside the house. Based on this alternative meaning, my friend's father believed he was perfectly entitled to meet his neighbour in his garden shed and had proceeded to do so. He could not see that the meaning of 'outdoors' had shifted from the meaning that the Government had intended in premise one to a quite different meaning that was not intended 
by the Government in premise two. In fact, in premise two, the garden shed is exactly the type of poorly ventilated, confined space where transmission of the virus is likely to occur and that the Government was still eager to prohibit in its amended advice. The logical error in this case is linked to an illicit shift in the meaning of the word 'outdoors' in the two premises of this argument. Logicians have historically characterized this shift as the fallacy of equivocation.

The four scenarios examined in this section illustrate the type of logical difficulties members of the public had in negotiating the restrictions that came into force during lockdown in the UK. They are by no means unique. Fallacious reasoning was a daily occurrence as people grappled with new public health measures designed to control the spread of the virus. But, of course, the public was not alone. Public health agencies around the world were facing a growing demand to provide clear and accurate information about the virus and guidance on how people could protect themselves against it. This demand was particularly acute from groups such as health and care workers, people in high-risk occupational roles (e.g., bus drivers), and individuals in vulnerable populations (e.g., people with diabetes) who were perceived to be at greater risk of contracting the virus and/or developing severe COVID-19 disease if they did become infected. Public health agencies, such as the CDC in the United States and the WHO, had to formulate advice and guidance at a time when relatively little was still known about this novel coronavirus. The strategies they used for this purpose are also an important part of the reasoning that was used during the COVID-19 pandemic. In the next section, we examine some of those strategies and consider how they shaped the response of key public health agencies during the early weeks and months of the pandemic.

\section{Public health agencies}

Public health agencies are at the forefront of the global response to COVID-19. Within public health agencies, I include any government department or independent agency whose role it is to monitor public health and to institute measures that protect public 
health. This includes Public Health England, an executive agency of the Department of Health and Social Care in the UK. It also includes the WHO, a United Nations agency with offices and personnel around the world that operates at arm's length from governments. A key part of the remit of these bodies is to communicate clearly with the public and healthcare professionals about the risks that this new virus poses to human health. This is a formidable task because these various agencies are learning about this virus even as they are expected to provide expert advice to others. Public health agencies must issue guidance in the absence of complete data on the nature and behaviour of this virus. Cautious decision-making is central to the advice they offer, particularly in a context where evidence is incomplete and the consequences of incorrect information for human health could be very grave indeed.

Against this backdrop, much of the initial guidance offered by these agencies has been based on analogical reasoning. With two other beta coronaviruses (SARS-CoV and MERS-CoV) as analogues, it has been possible for these agencies to formulate early guidance for the public and for health professionals on critical issues, such as infection control, transmission properties, incubation period, and so on. The following statements illustrate the widespread use of SARS-CoV and MERS-CoV as analogues in reasoning by Public Health England, the CDC in the United States, and the WHO.

\section{Public Health England: environmental survival}

"In light of limited data for SARS-CoV-2, evidence was assessed from studies conducted with previous human coronaviruses, including MERS-CoV and SARS-CoV. Human coronaviruses can survive on inanimate objects and can remain viable for up to 5 days at temperatures of 22 to $25^{\circ} \mathrm{C}$ and relative humidity of 40 to $50 \%$ (which is typical of air-conditioned indoor environments)" (Public Health England 2020). 
Centers for Disease Control and Prevention: transmission properties and incubation period

"2019-nCoV is similar to coronaviruses that cause MERS and SARS, which are transmitted mainly by respiratory droplets" (Patel et al. 2020: 140).

"Based on the incubation period of illness from MERS and SARS coronaviruses, CDC believes that symptoms of 2019-nCoV infection occur within 2 to 14 days following infection" (Patel et al. 2020: 140).

World Health Organization: infection control guidance for health workers

"Based on experience with SARS and MERS and known modes of transmission of respiratory viruses, infection and prevention control guidance were published to protect health workers recommending droplet and contact precautions when caring for patients, and airborne precautions for aerosol generating procedures conducted by health workers." (World Health Organization 2020b)

Analogical reasoning based on SARS-CoV and MERS-CoV provides a rationally warranted basis for the early responses to COVID-19 from these public health agencies. There was already evidence established that the virus that causes COVID-19 has phylogenetic and immunologic similarities to SARS-CoV. An analysis of genome composition revealed that there are only 380 amino acid substitutions between SARS coronaviruses and the COVID-19 coronavirus, with most of these substitutions concentrated in the non-structural protein genes ( $\mathrm{Wu}$ et al. 2020). The spike protein on the surface of the virus that causes COVID-19 uses the same receptor-angiotensin converting enzyme II (ACE2) - as SARS-CoV to access the cells of its human host. Given these similarities, it was reasonable for scientists to conclude that SARS-CoV was a sound starting point from which to offer guidance and information about COVID-19. If the COVID19 virus shared these basic similarities with SARS-CoV, it was argued, then it was likely to share other features with the SARS 
coronavirus. The argument has the following form, where $a$ and $b$ represent phylogenetic and immunologic attributes, and $c$ represents attributes such as transmission properties and incubation period:

SARS-CoV has attributes $a, b$, and $c$.

The COVID-19 virus has attributes $a$ and $b$.

Therefore, the COVID-19 virus probably has attribute $c$ also.

For public health agencies charged with managing the response to COVID-19, analogical reasoning was a rationally warranted strategy. The emergence of a novel virus is a challenging scenario for public health agencies. To protect public health, these agencies must make decisions and take courses of action in advance of complete data. Analogical reasoning provides a tentative basis on which to move forward in our understanding of a novel virus until such times as more data becomes available (Cummings 2004; 2014a; 2014b; 2020). This data may show that some of our early judgements are mistaken and must be rejected. But this is preferable to inaction that can cost lives and erode trust in public health agencies if we avoid analogical reasoning (Cummings 2014c). However, if we adhere too rigidly to analogical reasoning in our thinking, it can also become a barrier to a better understanding of a novel pathogen. We may accept too readily that a new virus must have certain transmission properties or an incubation period of a set duration because this is the way related viruses behave. A facilitative strategy based on analogical reasoning can become an obstructive strategy if it prevents us from seeing the way in which a new virus differs from other viruses, even those viruses with which it shares certain properties. The WHO (2020c) cautions against the over-reliance on better known pathogens like SARS$\mathrm{CoV}$ and influenza to understand COVID-19. In its report on the WHO-China Joint Mission regarding COVID-19, it states that "building scenarios and strategies only on the basis of well-known pathogens risks failing to exploit all possible measures to slow transmission of the COVID-19 virus, reduce disease and save lives" (p. 18). Public health agencies can avoid this scenario by rigorously testing the analogies used in their decision-making 
about COVID-19 and relinquishing those that are no longer productive.

Another rationally warranted reasoning strategy used by public health agencies during the COVID-19 pandemic was the argument from ignorance. This one-premise argument typically has the following form:

There is no evidence that $X$ is true ( $X$ is false).

Therefore, $X$ is false ( $X$ is true).

This argument is widely viewed as a fallacy because a lack of evidence or knowledge, it is claimed, cannot be used as grounds to accept a proposition as true (or false) (Krabbe 1995; Woods and Walton 1978; Walton 1995). However, in public health and other contexts (e.g., law), there are circumstances where this is not so clearly the case (Cummings 2002; 2011; 2015a; 2015b; Walton 1992b). Imagine a scenario in which I want to establish whether guests at a wedding have been exposed to the salmonella bacterium in the food that is served to them at the event. A team of environmental health officers may take samples of the food that was served to guests and test them for the presence of the bacterium. They may also examine the conditions of the kitchens in which the food was prepared. The staff who prepared and served the food may also undergo health screening to establish if they are infected with salmonella and could have contaminated the food they were preparing. The guests may also be tested to see if they are infected with salmonella. Finally, health officials examine in detail all the information they have gleaned from their various investigations. If no trace of the salmonella bacterium can be found, then there are strong grounds indeed for concluding that the guests at the wedding were not exposed to salmonella in the food that they consumed. The reasoning in this case takes the form of a rationally warranted argument from ignorance:

There is no evidence that the guests at the wedding were exposed to salmonella.

Therefore, the guests at the wedding were not exposed to salmonella. 
The reason this argument is rationally warranted is that it satisfies two conditions: a closed-world assumption and an exhaustive search criterion. The closed-world assumption (Reiter 1987) requires a knowledge base in a domain to be fully closed in the sense that it contains all the information that relates to a topic or issue (in this case, salmonella infection at a wedding). The exhaustive search criterion requires that the content of the knowledge base is fully examined so that if it contains information of relevance (e.g., a positive test result for salmonella in one of the catering staff), then that information will be discovered. When both of these conditions are satisfied, as they are in our salmonella example, then there are very strong grounds for concluding that a proposition is false (true) on the grounds that there is no evidence that the proposition is true (false).

What role does the argument from ignorance play in relation to COVID-19? One of the issues that governments and health authorities around the world grappled with during the early months of the pandemic was antibody tests. If people could be tested and shown to have antibodies to the COVID-19 virus, then it was believed they would have immunity to the virus and could avoid further infection. This would allow people with a positive test result to travel and work safely and generally resume a more normal pattern of economic activity. However, the WHO repeatedly urged caution about antibody tests. Even if such a test could be developed, the presence of antibodies in a person's blood serum could tell us nothing about their immunity to further infection. Antibodies to the COVID-19 virus may only offer a person protection for a short period of time, if they offered protection at all. Only clinical and epidemiological studies could address the issue of immunity, and these studies were still some way off in the future. The WHO was keen to emphasize that an antibody test per se could not address immunity, as the remarks from one of its chief scientists indicate. Dr Maria van Kerkhove, head of WHO's Emerging Diseases and Zoonoses Unit and part of its Joint Mission to China, stated the following in a press briefing on April 18, 2020: 
There are a lot of countries that are suggesting using rapid diagnostic serological tests to be able to capture what they think will be a measure of immunity. Right now, we have no evidence that the use of a serological test can show that an individual has immunity or is protected from reinfection (Boseley 2020, emphasis added).

The no evidence claim in Dr van Kerkhove's statement was intended to underline the WHO's position that optimism about antibody tests was unwarranted, as these tests could not be used to establish an individual's immunity to further COVID-19 infection, which many people and governments had falsely assumed. To this extent, her no evidence statement forms the premise in an argument from ignorance:

There is no evidence that current serological tests can establish an individual's immunity.

Current serological tests cannot establish an individual's immunity.

For this argument from ignorance to be rationally warranted, it must satisfy our earlier conditions: the closed-world assumption and the exhaustive search criterion. How well does this argument measure up to these conditions? In its coordination of the global response to COVID-19, the WHO was ideally placed to know which serological tests were in development and to assess their state of readiness to undertake antibody testing. This is part of the organization's remit in diagnostics that includes not just serological tests to test for the presence of antibodies, but also the antigen test (polymerase chain reaction test) that could establish the presence of the virus in someone who is infected. WHO's database on serological testing was almost certainly a closed knowledge base in the sense of containing information on all available serological tests, regardless of their origin and stage of development. As well as being closed, this knowledge base was also exhaustively searched. It is inconceivable that a WHO scientist, like Dr van Kerkhove, would not have detailed knowledge of the serological tests currently available and what these tests could and could not achieve. She would know, for example, that these tests could not 
be used to test for the presence of the virus, as antibodies often appear some time after infection with a pathogen has taken place. She would also know that serological tests could not be used to establish an individual's immunity, as the presence of antibodies alone can tell us nothing about future immunity to the COVID-19 virus. In short, Dr van Kerkhove was in possession of a closed knowledge base on serological tests that had been exhaustively searched. An absence of evidence in this case provided considerable rational warrant for her claim that current serological tests cannot establish immunity.

With false and misleading claims about serological tests taking hold early in the COVID-19 pandemic, the WHO was compelled to address these claims. It was important to dispel the idea that serological tests could be used to give people "immunity passports" (World Health Organization 2020d), as media outlets and governments were suggesting at the time. The argument from ignorance allowed this misconception of serological tests to be unambiguously rejected, whilst allowing for the possibility that future clinical and immunologic studies might succeed in establishing the significance of antibodies to an individual's immunity. But at this early stage in the COVID-19 pandemic, the WHO (2020d) wanted its key message to be clear: "As of 24 April 2020, no study has evaluated whether the presence of antibodies to SARS-CoV-2 confers immunity to subsequent infection by this virus in humans." No current serological test could establish immunity, and efforts to use such tests for this purpose were misguided. The argument from ignorance allowed this claim to be rejected until such time as a development of the evidence base permitted it to be re-examined.

\section{Conclusion}

This article has examined some of the good and bad reasoning that occurred early in the COVID-19 pandemic. The general public displayed various lapses of reasoning when the lockdown came into force in the UK. Logical errors arose as people tried to adapt, not always successfully, to the new restrictions in place. Some of these errors were recognizable fallacies according to traditional 
lists (e.g., equivocation). Other errors were more difficult to classify based on traditional lists of fallacies, although they were nonetheless instances of bad reasoning. Individuals were not alone in deciding how to respond to the COVID-19 crisis. Public health agencies also had to adapt their reasoning to deal with the challenges that COVID-19 posed. Analogical reasoning based on SARS-CoV and MERS-CoV was a mainstay of early public health advice on everything from infection control and transmission to the incubation period and environmental survival of the virus. The argument from ignorance was employed to good effect to reject mistaken conceptions about the role of antibody testing in the global fight against the virus. These instances of good and bad reasoning were not unique, and they will undoubtedly be repeated many times as the COVID-19 pandemic unfolds. However, they do illustrate the ways in which good and bad reasoning can facilitate and compromise compliance with public health measures, respectively, during a critical period in the response to this novel coronavirus.

I want to conclude by addressing two implications of this work for scholars of reasoning. First, public health recommendations often assume a rational citizenry that can form logical judgements about health behaviours. As the discussion of this article demonstrates, this assumption is not always warranted. But herein lies a valuable opportunity for scholars of reasoning, I believe. In any country's effort to educate its population, I contend that critical thinking is as important to that effort as instruction in basic literacy and numeracy. Why should entrants to university be the only people to avail of critical thinking courses or other instruction in how to evaluate claims and evidence? There is a public education gap in reasoning and critical thinking, and it must be addressed, particularly as it relates to health. Scholars of reasoning have the conceptual tools and practical skills to address this gap, and I urge them to now do so. This application of their work would have a significant beneficial impact on the quality of public health action and decision-making.

But scholars of reasoning have another role that they can perform. It is so often the case that examination of reasoning during health crises takes place after these crises have occurred and an 
infectious disease or other threat has already taken a serious toll on human health. This is the character of much of my own work, such as when I conducted a detailed analysis of the reasoning that unfolded during the bovine spongiform encephalopathy (BSE) epidemic in British cattle in the 1980s and 1990s (Cummings 2010). But scholars of reasoning should be able to influence the decisionmaking of policy makers, health agencies, and government advisory bodies in real time. Rather than acting as spectators and observing the work of groups like the Scientific Advisory Group for Emergencies (SAGE) - the expert group that provides advice to the UK Government on COVID-19-scholars of reasoning should sit alongside the epidemiologists, statisticians, virologists, and microbiologists who form the membership of these groups. Decisions should be rationally scrutinized as they are taken and not at a later point in time when any negative consequences arising from them cannot be reversed. This would represent a moment of profound change, with scholars of reasoning playing an integral role in health decision-making on a par with medical and other scientists. If this could be the legacy of COVID-19, subsequent generations might be more adept at responding to the global pandemics that will inevitably afflict them.

\section{Acknowledgements}

The author gratefully acknowledges the comments of two reviewers on an earlier version of this article.

\section{References}

Boseley, Sarah. 2020, April 20. WHO warns that few have developed antibodies to Covid-19. The Guardian. URL accessed 9 December 2020: https://www.theguardian.com/society/2020/apr/20/studiessuggest-very-few-have-had-covid-19-without-symptoms

Cummings, Louise. 2002. Reasoning under uncertainty: The role of two informal fallacies in an emerging scientific inquiry. Informal Logic 22(2): 113-136.

Cummings, Louise. 2004. Analogical reasoning as a tool of epidemiological investigation. Argumentation 18(4): 427-444.

Cummings, Louise. 2010. Rethinking the BSE crisis: A study of scientific reasoning under uncertainty. Dordrecht: Springer. 
Cummings, Louise. 2011. Considering risk assessment up close: The case of bovine spongiform encephalopathy. Health, Risk \& Society 13(3): 255-275.

Cummings, Louise. 2014a. Analogical reasoning in public health. Journal of Argumentation in Context 3(2): 169-197.

Cummings, Louise. 2014b. Circles and analogies in public health reasoning. Inquiry 29(2): 35-59.

Cummings, Louise. 2014c. The 'trust' heuristic: Arguments from authority in public health. Health Communication 29(10): 1043-1056.

Cummings, Louise. 2015a. The use of 'no evidence' statements in public health. Informal Logic 35(1): 32-65.

Cummings, Louise. 2015b. Reasoning and public health: New ways of coping with uncertainty. Cham, Switzerland: Springer.

Cummings, Louise. 2020. Fallacies in medicine and health: Critical thinking, argumentation and communication. Houndmills, Basingstoke: Palgrave Macmillan.

Hammer, Lea, Polly Dubbel, Ian Capron, Andy Ross, Amber Jordan, Jaxon Lee, Joanne Lynn, Amelia Ball, Simranjit Narwal, Sam Russell, Dale Patrick and Howard Leibrand. 2020. High SARS-CoV-2 attack rate following exposure at a choir practice - Skagit County, Washington, March 2020. Morbidity and Mortality Weekly Report 69(19): 606-610.

James, Allison, Lesli Eagle, Cassandra Phillips, D. Stephen Hedges, Cathie Bodenhamer, Robin Brown, J. Gary Wheeler and Hannah Kirking. 2020. High COVID-19 attack rate among attendees at events at a church - Arkansas, March 2020. Morbidity and Mortality Weekly Report 69(20): 632-635.

Jing, Qin-Long, Ming-Jin Liu, Jun Yuan, Zhou-Bin Zhang, An-Ran Zhang, Natalie E. Dean, Lei Luo, Meng-Meng Ma, Ira Longini, Eben Kenah, Ying Lu, Yu Ma, Neda Jalali, Li-Qun Fang, Zhi-Cong Yang and Yang Yang. 2020. Household secondary attack rate of COVID19 and associated determinants. medRxiv2020.04.11.20056010. URL accessed 15 June 2020:

$<$ https://doi.org/10.1101/2020.04.11.20056010>.

Kimball, Anne, Kelly M. Hatfield, Melissa Arons, Allison James, Joanne Taylor, et al. 2020. Asymptomatic and presymptomatic SARS-CoV-2 infections in residents of a long-term care skilled nursing facility King County, Washington, March 2020. Morbidity and Mortality Weekly Report 69(13): 377-381.

Krabbe, Erik C.W. 1995. Appeal to ignorance. In Fallacies: Classical and contemporary readings, eds. Hans V. Hansen and Robert W. Pin- 
to, 251-264. University Park, PA: The Pennsylvania State University Press.

Lam, T. T., N. Jia, Y. Zhang, et al. 2020. Identifying SARS-CoV-2 related coronaviruses in Malayan pangolins. Nature. https://doi.org/10.1038/s41586-020-2169-0

Pan, Xingfei, Dexiong Chen, Yong Xia, Xinwei Wu, Tangsheng Li, Xueting Ou, et al. 2020. Asymptomatic cases in a family cluster with SARS-CoV-2 infections. The Lancet Infectious Diseases 20(4): 410411.

Park, Shin Young, Young-Man Kim, Seonju Yi, Sangeun Lee, Baeg-Ju $\mathrm{Na}$, Chang Bo Kim, et al. 2020. Coronavirus disease outbreak in call center, South Korea. Emerging Infectious Diseases 26(8). https://doi.org/10.3201/eid2608.201274

Patel, Anita, Daniel B. Jernigan, and 2019 n CoV CDC Response Team 2020. Initial public health response and interim clinical guidance for the 2019 novel coronavirus outbreak - United States, December 31, 2019-February 4, 2020. Morbidity and Mortality Weekly Report 69(5): 140-146.

Powers, Lawrence H. 1995. Equivocation. In Fallacies: Classical and contemporary readings, eds. Hans V. Hansen and Robert W. Pinto, 287-301. University Park, PA: The Pennsylvania State University Press.

Public Health England. 2020. Guidance: Transmission characteristics and principles of infection prevention and control. URL accessed 13 June 2020: <https://www.gov.uk/government/publications/wuhannovel-coronavirus-infection-prevention-and-control/transmissioncharacteristics-and-principles-of-infection-prevention-and-control>.

Reiter, Raymond. 1987. Nonmonotonic reasoning. Annual Review of Computer Science 2: 147-186.

Walton, Douglas N. 1990. Ignoring qualifications (secundum quid) as a subfallacy of hasty generalization. Logique \& Analyse 33(129/130): 113-154.

Walton, Douglas N. 1992a. Which of the fallacies are fallacies of relevance? Argumentation 6(2): 237-250.

Walton, Douglas N. 1992b. Nonfallacious arguments from ignorance. American Philosophical Quarterly 29(4): 381-387.

Walton, Douglas N. 1995. Arguments from ignorance. University Park, PA: Pennsylvania State University Press.

Walton, Douglas N. 1996. Fallacies arising from ambiguity. Dordrecht: Springer Science + Business Media.

Walton, Douglas N. 1999. Rethinking the fallacy of hasty generalization. Argumentation 13(2): 161-182. 
Walton, Douglas N. 2004. Relevance in argumentation. Mahwah, New Jersey: Lawrence Erlbaum Associates, Inc.

Woods, John. 2004. The death of argument. Applied Logic Series, volume 32. Dordrecht: Springer.

Woods, John and Douglas N. Walton. 1978. The fallacy of 'Ad ignorantiam'. Dialectica 32(2): 87-99.

World Bank. 2020. Global economic prospects, June 2020. Washington, DC. World Bank.

$<$ https://www.worldbank.org/en/publication/global-economicprospects>

World Health Organization. 2020a. WHO coronavirus disease (COVID19) dashboard. URL accessed 9 June 2020: $<$ https://covid19.who.int/>.

World Health Organization. 2020b. WHO timeline - Covid-19. URL accessed 14 June 2020: <https://www.who.int/news-room/detail/2704-2020-who-timeline---covid-19>.

World Health Organization. 2020c. Report of the WHO-China joint mission on coronavirus disease 2019 (COVID-19). Geneva, Switzerland: World Health Organization. <https://www.who.int/docs/defaultsource/coronaviruse/who-china-joint-mission-on-covid-19-finalreport.pdf $>$

World Health Organization. 2020d. "Immunity passports" in the context of COVID-19. Scientific Brief, 24 April 2020. URL accessed 15 June 2020:

$<$ https://www.who.int/news-room/commentaries/detail/immunitypassports-in-the-context-of-covid-19>.

$\mathrm{Wu}$, Aiping, Yousong Peng, Baoying Huang, Xiao Ding, Xianyue Wang, Peihua Niu, Jing Meng, et al. 2020. Genome composition and divergence of the novel coronavirus $(2019-\mathrm{nCoV})$ originating in China. Cell Host \& Microbe 27: 325-328.

Yang, Xiaobo, Yuan Yu, Jiqian Xu, et al. 2020. Clinical course and outcomes of critically ill patients with SARS-CoV-2 pneumonia in Wuhan, China: A single-centered, retrospective, observational study. Lancet Respiratory Medicine 8(5): 475-481. 